Operative Akinesia. - The enormous influence of the extra-ocular muscles on the intra-ocular pressure demonstrates the necessity for adequate akinesia in all intra-ocular operations. When it is remembered that a relatively mild contraction of the orbicularis raises the intra-ocular pressure from 27 to $53 \mathrm{~mm}$. $\mathrm{Hg}$, the danger of loss of vitreous in a cataract extraction is obvious unless this muscle is thrown out of action. It follows that in all such operations the orbicularis should be paralysed, either by injection of the facial nerve as it crosses the ramus of the mandible or by a local injection around the orbit: the former method is the prettier, the latter the easier and more certain. Further, the action of looking down raises the pressure of the eye by the contraction of the recti, a rise which becomes quite marked if the action is forced. If every precaution is to be taken, a retro-bulbar injection of novocaine should be employed. This should be employed as a very dilute $(0.25$ or 0.5 per cent.) solution injected immediately before commencing the operation so that the muscles are not wholly paralysed but merely weakened, allowing the patient to look down but not to do so forcibly; or alternatively, a stitch should be inserted into the superior rectus so that the eye can be adequately controlled. Such a procedure incidentally infiltrates the ciliary ganglion thus rendering the inner eye completely anaesthetic, and results in a degree of immobility and control which has to be seen to be believed.

\title{
REFERENCES
}

Colle, J., Duke-Elder, W. S. and Duke-Elder, P. M.-Jl. Physiol., Vol. LXXI, p. 1. 1931.

Duke-Elder, W. S.-Ji. Physiol., Vol. LXI. p. 409, 1926,

Duke-Elder, P. M. and W. S.-Proc. Roy. Soc. (B), Vol. CVII, p. 332, 1930.

Duke-Elder, P. M. and W. S., and Colle. J.-Brit. Jl. Ophthal.

Note.-Blocks for illustrations, Fig. Nos. 1, 2, 3, 4, 7, 9, 10 and 17, kindly lent by Henry Kimpton.

\section{SIR WILLIAM READ'S TREATISE OF THE EYES}

BY

\section{ARNOLD SORSBY}

LONDON

AcCoRDING to Hirschberg, Sir William Read published a "Treatise of the eyes containing a short, but exact, description of the structure, situation . . . as also causes, symptoms and cures of 130 diseases incident to them," London, 1706. This information, he states, is obtained from the Biog. Lexicon, Vol. IV, 683; Haller, Bib. chir., 1,574, only gives the short title "Diseases of the Eye, 1706," taken over by Beer, Rep., Vol. I, 12. Neither Haller nor Beer seems to 
have seen the book. Nor could Hirschberg find it in either the German or English libraries.

T. H. Shastid, in the American Encyclopaedia of Ophthalmology, gives the' same title as Hirschberg, and adds that the book seems to be no longer extant.

The Dictionary of National Biography gives a different name for Read's book: "A short but exact Account of all the Diseases incidental to the Eyes," whilst the date is the same, 1706. The book was obviously seen by the writer of the notice (Thomas Seccombe) for a reference is made to some of its contents (the cures

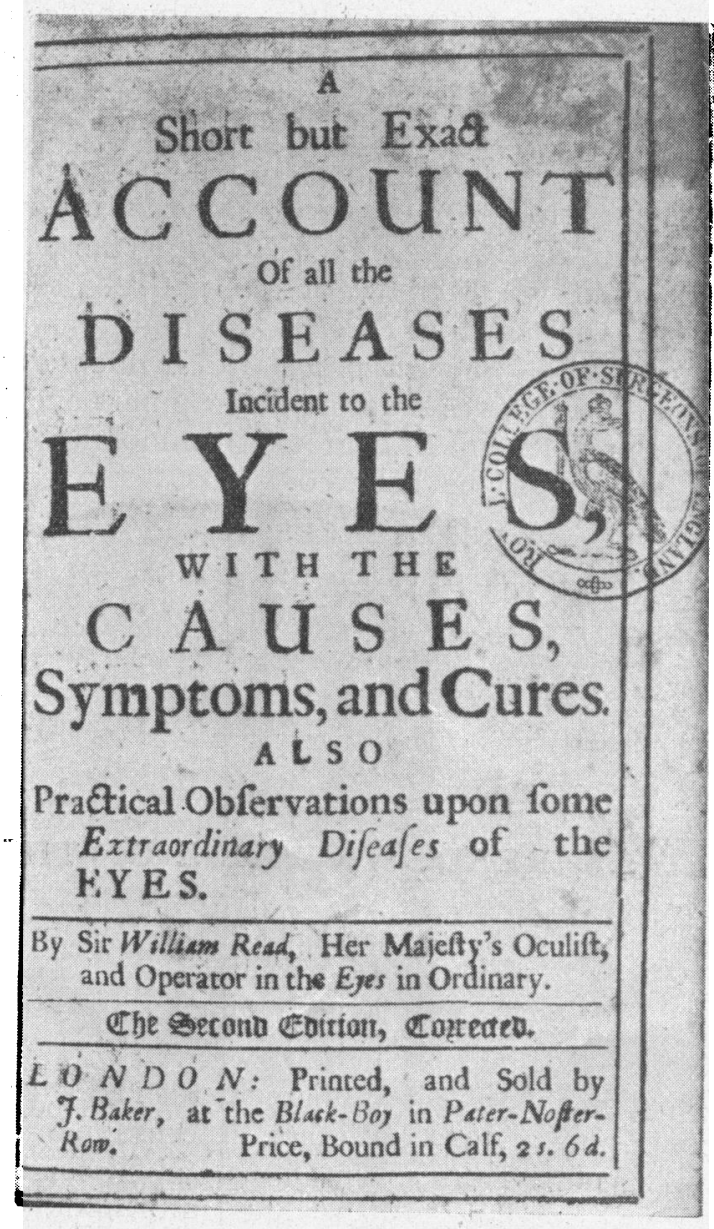

FIG. 1.

Title page of book described in Dictionary of National Biography and by R. R. James. 
by Read's styptic water reported in "the latter portion of the work.")

R. R. James gives an excellent account of the book mentioned in the Dictionary of National Biography. James states that the work is " rather a scarce item; the Library of the Ophthalmological Society does not contain a copy of it, but there is one in the Library of the Royal Society of Medicine." The transcript given of the title page does not contain any date of publication, but James states that the book appeared in 1706 .

To this information, conflicting as to the title of the book published by Read in 1706, must be added the fact that the book as given by Dictionary of National Biography and James, is entered in the Catalogue of the British Museum as a second edition. (No first edition of a book by Read is entered). The fact that the book is a second edition seems to be taken from the title page, which states " The Second Edition, Corrected," a statement also to be found on the copy in the possession of the Royal Society of Medicine (Fig. 1). Both these copies have no date of publication. A third copy, in the possession of the Royal College of Surgeons, differs in no way from the two others. No book by Read is indexed in the Catalogue of the Surgeon-General's Library.

If these facts are to be taken on their face values, Sir William Read, quack, mountebank and oculist to Queen Anne, and to George the First, is the author of two books on the diseases of the eyes, both published in 1706 ; one of these books went into a second edition; and of these three books, only three copies of the second edition of "A Short but Exact, etc.," are extant.

The position, however, is distinctly less complicated. The difficulty is solved by a copy in the possession of the Royal College of Surgeons. This bears the title indicated by Hirschberg, as can be seen from the accompanying photograph (Fig. 2). No other copy of this work could be traced in London.

A comparison of these two books shows the text is identical, in spite of the difterent title pages. The "second edition, corrected" of "A short but exact Account, etc." is not a second edition of a first edition no longer extant, but of the presumably earlier "Treatise of the Eyes." Furthermore, the "second edition corrected" is certainly not more than a reprint in which there is no modification to the extent of a comma; the type had clearly not been reset.

The title pages of both these books are undated. But, in the "Treatise of the Eyes" there is a subsidiary title page which follows p. 162 and precedes the "Practical observations relating to extraordinary diseases of the eyes." This page is shown in Fig. 3 ; it bears the date 1706. No such title page is present in the three copies of the "Short but exact account," but seems to have been 
there at some time or other; for an unevenly cut margin is clearly seen in all the three copies, and is especially marked in the copy at the Royal College of Surgeons, in which the page has been so badly cut out that there remains in one place the black printed line which

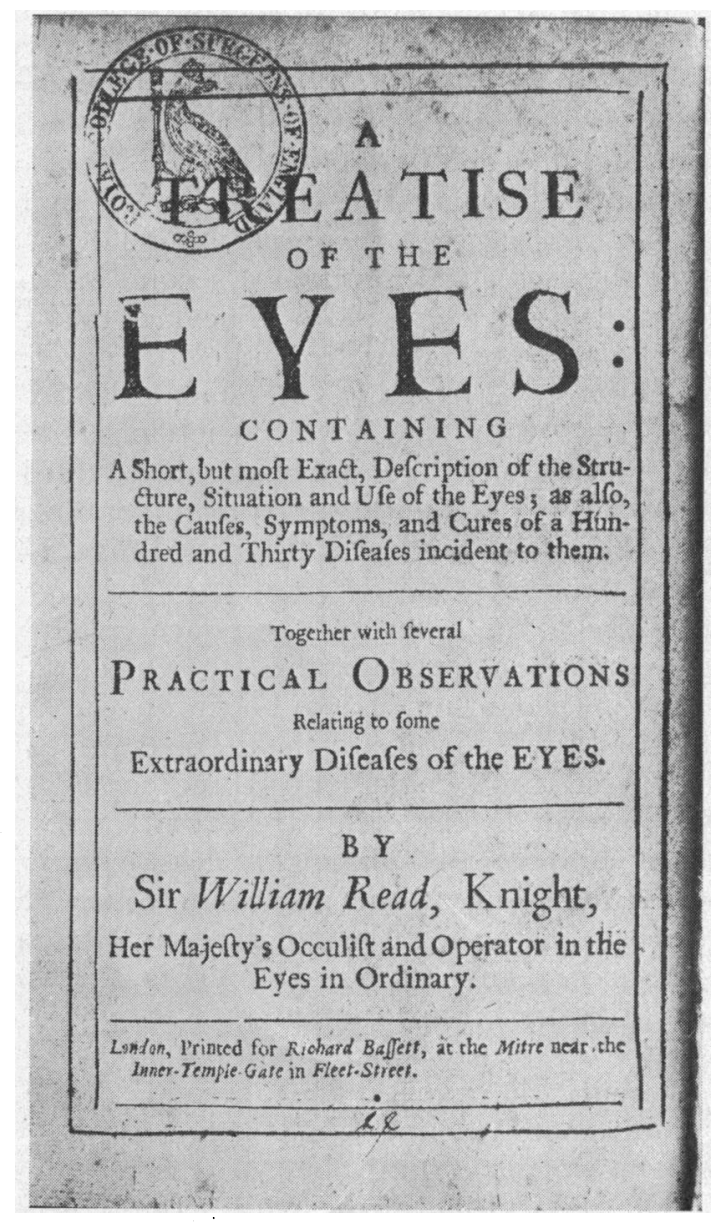

FIG. 2.

Title page of book mentioned by Hirschberg and regarded as no longer extant.

framed the contents of the title page. Furthermore, this section of Practical observations, etc., with its separate title page, is separately numbered, the title page being $[1,2]$ and the text beginning on p. 3. The separate numeration is present in the "second edition, corrected," but p. 3 follows immediately on 
p. 162. Absolutely conclusive is the fact that the $\mathrm{M}_{2}$-corresponding to pp. [1-2], is missing; $\mathrm{M}_{3}$ follows on $\mathrm{M}$; for this reason the British Museum enter their copy as damaged. The title page, with its date of 1706 , is thus omitted from "the second edition,

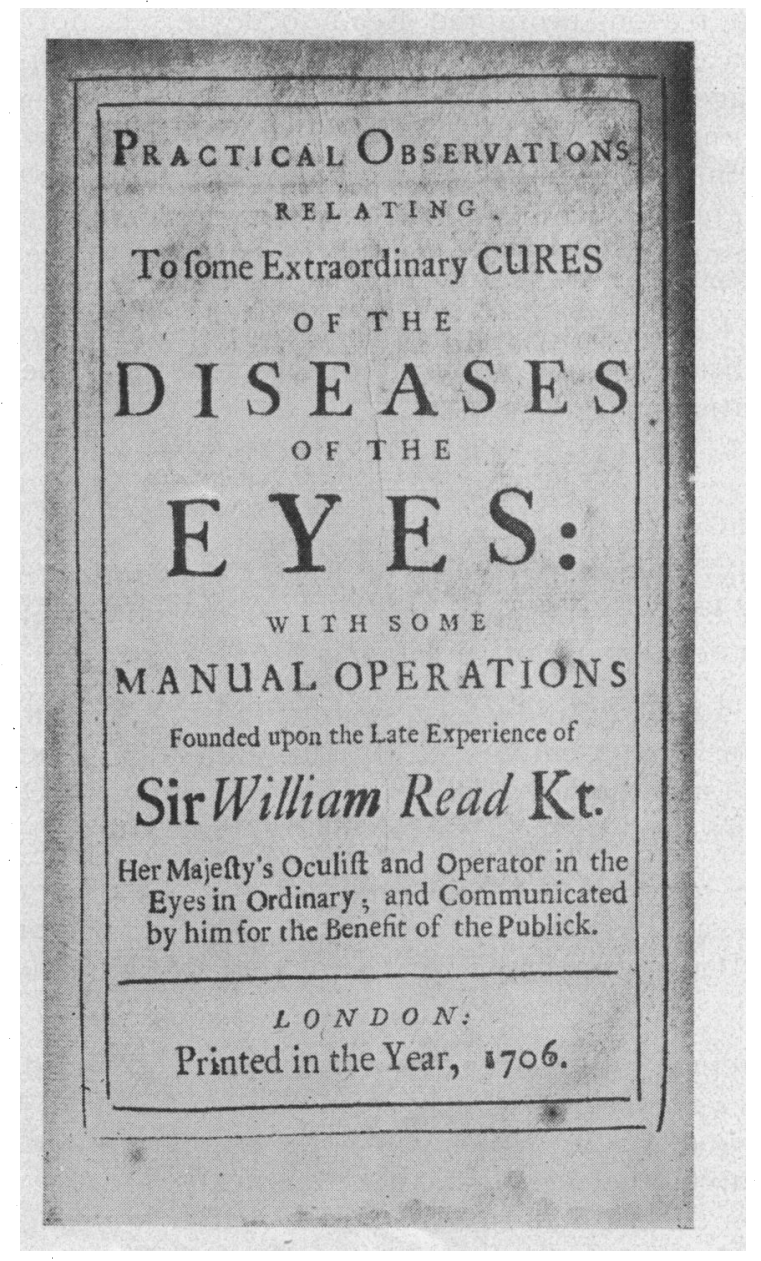

Fig. 3.

Subsidiary title page of book illustrated in Fig. 2.

corrected" by the simple process of excision, and the only other change in the book is the substitution of a different main title page. It should also be added that the original issue contains four pages at the end of the book, which are missing in the re-issue, these consisting of two-and-a-half pages of publisher's announcements of 
other books, the rest being blank. It would, therefore, appear that a second edition was never printed, the remains of the first and only edition being done up to bring out a "second edition, corrected." Presumably it was brought out after 1706, this probably being the reason why the subsidiary title page with its date was cut out. What reasons prompted Read to do this is not a matter of great significance. That some difference with the publisher was the cause is suggested by the fact that the title page of the first issue bears the imprint of the publisher; in the later title page the publisher's name is omitted and instead that of the printer and bookseller appears. Support to this view is lent by the omission in the re-issue of the four end pages containing the publisher's announcements.

Thus do Read's two Ophthalmic books, one of which went into a second edition, become reduced to one and the same production and publication.

But, if the titles and editions of Read's book must not be taken on their face value, the book itself is not devoid of interest. The text consists essentially of three parts:

(1) A 23-page introductory survey under 8 headings, the first being "Some errors committed by the pretended Practitioners for the Eyes," and the last "Of the Temperatures and Operations of most Simples used in the Diseases of the Eyes."

(2) The body of the book: pp. 24-162. This is divided into nine Books, all of which, except Book VII, have more than one chapter. It is a systematic treatise of the anatomy and diseases of the eye.

(3) Practical Observations relating to some extraordinary Cures, of the Diseases of the Eyes, by Sir William Read": 40 pages (42 less pp. [1 and 2] $\left(\mathrm{M}_{2}\right)$ missing in "the second edition, corrected" and taken up by the subsidiary title page in the Treatise of the Eye). 'This section is separately paged, and its matter is arranged under 10 headings, the first being "An extraordinary Cure of the Gutta Serena" and the last, "Several useful rules "concerning the Preservation of Sight."

The first part of the book contains some excellent observations written in a personal manner, on many points of importance in the diagnosis and treatment of blindness. It gives the impression of being the work of a careful observer and honest practitioner.

The second part is a concise, and on the whole excellent, summary of the teaching on diseases of the eyes to be obtained from 
the Greek-Arabian sources, to which constant reference is made. There is nothing original, but what there is, is lucid and well put. The account of the anatomy of the eye is, however, most unsatisfactory. Its teaching ignores altogether the work of the great anatomists and physiologists of the 17th century:- The lens is still the "first instrument of sight"; " other humours have no light of themselves, as hath the Chrystallina, which could not receive the light which it received outwardly, if it did not partake of the same within, and partake of it in such a manner that it agreed naturally with the same." The conjunctiva is still derived from the pericranium. This is not the anatomy and physiology of two centuries after the Renaissance, but an account of Galen's teaching. No up-to-date oculist of the beginning of the 18th century could possibly have been so backward in his knowledge. If the 17 th century marked little progress in clinical ophthalmology, it laid the firm basis for the remarkable clinical development in the 18th century through its brilliant pioneer work in anatomy and physiology, by Berengario, Fabricius, Ruysch, Fallopius, Keppler, Schreiner, Briggs, and a host of others. The writer of the chapter on the anatomy of the eye is totally oblivious of all this work.

The third section of the book, giving an account of some extraordinary Cures by Sir William Read is "Communicated by him for the benefit of the Publick." It is a vulgar, boasting account of the wonderful properties of his Styptick water for the cure of blindness and cancer; nor does the author hide the light of his superior skill under a bushel. There is nothing of any signiticance in this section: it is no better and no worse than the endless similar efforts of quacks of all ages and climes.

Two consecutive extracts from this section (pp. 17-19) will more than suffice:-

\section{An Extraordinary Case, of the stopping of a violent Effusion of Blood.}

To give you another Instance of the marvellous effects of a good Styptick, you must know that within a little time after was recommended to my Care, one Mrs. Noles of Hedscox, in the County of Suffolk. She had a Wen of at least Ten Pounds Weight upon her Right-Arm, which being a great hindrance to the use of the said Arm, she desired me to take it off; I leave it to the Judgment of all such as are truly vers'd in the Art of Surgery, Whether the cutting off of an Excrescency of such a bulk must not infallibly be subject to great hazards, were it only for the great effusion of Blood, which in all probability must be the consequence of such an Operation? However, relying upon the excellent qualities of my Styptick Water, I undertook and perform'd the Task, stopt the Blood, and cured the Wound by the external application of the before mentioned Water. 


\section{Another very difficult Case, of a Cancerous Excrescency in the Great Corner of the Eye.}

Near the same time, viz. in November, 1705, Was recommended to my Care Mr. Seedmore, my Lord Mainard's Butler, who being afflicted with a most dangerous Excrescency of a Cancerous Nature in the Great Corner of the Eye adjoining to the Nose, of an extraordinary bigness, I, after the use of proper Purges, Cordials and Phlebotomy, took away by Incision, and eradicated the whole Cancerous Excrescency, and by the only application of my Styptick Water, answer'd all the further indications of stopping the effusion of Blood, and healing up the Ulcer, by engendring of new and sound Flesh, without the least hindrance of the Sight of the Patient.

I have told you in some of the before-mentioned Cases of this Nature, that as the expelling of the corrosive malignant Humours contained in the Mass of the Blood, which occasion these pernicious Cancerous Ulcers, is endeavoured most commonly by the Practitioners, through the means of Alexipharmicks; so the stopping of the effusion of Blood, which in the ordinary consequence of such like Incisions, whereby the Cancer is totally eradicated, is generally performed by them by Searing. But, considering that the first of these two Remedies does not always answer the expectation of the Practitioner as well as of the Patient; and the second proves very often dangerous, or rather impracticable; by reason of the tenderness and situation of certain parts adjoining to the Cancerous Ulcer (as in the Cases of the Cancers in the Corner of the Eye) or by the spreading of the same malignant Ulcer, into a considerable compass, so as to extend to the great Veins; I have, to obviate these difficulties, prepared a peculiar Antidote appropriated to this Disease, and to be taken inwardly, and at the same time a Styptick Water, to answer all the ends that can be proposed by Searing, but with much more ease and less hazard; the same by its Astringent and Balsamick Quality, not stopping the Effusion of Blood only, but also healing up the Ulcer, without any dangerous Symptoms.

The book is thus a most incongruous production. There is able introductory matter in which good clinical observations are sadly mixed up with " a decided smack of Culpepper" as James puts it. This is followed by a good account of the current teaching of the diseases of the eye, but the description of the anatomy and physiology of the eye is decidedly behind the times. Coming on top of these expositions, written dispassionately and on the whole in a satisfactory manner, is the final section which is a purely personal vainglorious rhodomontade. There is a scientific approach in the first two sections, though one section strikes a personal note and the other is in the strict tradition of good text-book writing. But the third section betrays no scientific knowledge or critical faculty whatever; the author's dexterous Hand and Styptick Water is the burden of its song-admittedly sung for the 
Benefit of the Publick. Only a man who at one and the same time could be ignorant and yet full of knowledge of Greek and Arabian literature, thoroughly uncritical and yet a good and honest observer, well acquainted with the classical medical literature, and yet totally oblivious of revolutionary changes introduced during the century preceding his own period-could possibly have written Read's Treatise of the Eyes. The impossible creature postulated never existed, not even in the person of Read, and Read's book could never have been written by Sir William Read. But if the oculist did not write it, the mountebank had a good deal to do with it.

It was the mountebank who came across a copy of "A treatise of one hundred and thirteene diseases of the Eyes, and Eye-Liddes. The second time published, with some profitable additions of certain principles and experiments, by Richard Banister, Mr. in Chyrurgery, Oculist and Practitioner in Physicke ... London . . 1622." No subsequent edition of this book is known, so it is likely to have been forgotten and scarce by 1706 , and posterity is indebted to Read that he gave it a new lease of life at the beginning of the 18th century, for it did not deserve oblivion. That Read should have seen fit to pass it off as his own production is a doubtful compliment to the excellency of this book; perhaps posterity ought to be grateful that he did not attempt to improve it before re-publication.

The incongruity of Sir William Read's Treatise of the Eyes is not a problem of a multiple personality of the author; it is merely the expression of an ill-balanced juxta-apposition. The first and second parts of Read's book, one giving the personal experience of an honest observer and the other a systematic though out-of-date treatise on the eyes is "lifted" from Banister. Read's own contribution consists of the third part-an achievement that is not incongruous with Read's character, knowledge and ability.

If Read did not attempt to add to the matter he lifted, he did attempt some excision, particularly in the first part of Banister's book, that known as Banister's Breviary of the Eyes. The second part, the systematic treatise of the anatomy and diseases of the eyes is reprinted practically in full, with only an occasional verbal alteration of no significance. The only parts omitted are the preface of one-and-a-half pages (about 200 words) and the marginal headings and references. For reasons best known to himself, Read did attempt to bring the hopelessly archaic anatomical description up to date.

$\mathrm{He}$ is, however, much more drastic with the first part of the book - the reprint from Banister's Breviary. Here the text is pruned, and as much as one whole paragraph, the opening one, actually 
re-written. As this is about the most radical change in the transcription, parallel passages may be of interest.

\section{BANISTER:}

ERROURS AMONGST MANY THAT PRACTISE FOR THE EYES.

It is an usual custome, as soon one complaineth of paine or griefe of the eyes, to have amongst twenty women, nineteene severall medicines told presetly, little notice of the nature of the disease being taken and the power of the medicines almost altogether unknowne.

I will describe the severall meanes which are commonly used and advised to be used by those, who without feare or iudgment use any medicine for any disease of one particular part.
READ :

SOME ERRORS COMMITTED BY THE PRETENDED PRACTITIONERS FOR THE EYES.

Nothing being more common, than as soon as a Patient complains of Pain, or any other Grief of the Eyes, to have recourse to all sorts of Medicines, without any regard to their Vertues or the true Nature of the disease, I will describe the several Remedies commonly used and advised by those who without Fear or Judgment use any Medicine for any Disease of one particular part.

Banister's Breviary is an intensely personal document. $\mathrm{He}$ relates how he met "one that had such a cataract at Walshingham in Norfolk" and how he "was sent for from Stamfort, to a Gentleman of great worth in London ;" he speaks of another case "at a place called Bridge Casterton near Stafford"; he gives "another Instance of this kind, At old Debnum in Suffolk . .." and relates of "Another in Newgate-Market in London, at the black boy." $\mathrm{He}$ also tells of what has been related to him concerning "a Beerbrewer in Southwark;" and further that "having by frequent and reitrated Experience, observed great variety of Symptoms and Accidents in the couching of Cataract, I will in their place discover some of them for the satisfaction of the careful Operator and the ease of the aggrieved Patient." All these personal notes, written in 1621 , appear as fresh as ever under Read's name in 1706 . It must be granted, to Read's credit, that if he did not add one syllable of text, the passages he omitted are not of great value.

Read's indebtedness is not confined to Banister, for what passes as Banister's Treatise is not the work of Banister only. The systematic treatise as distinct from the Breviary is a translation from Jacques Guillemeau's Maladies de l'Oeil, published in Paris in 1585. The history of this book in its English translation, and Banister's share in its production, is a problem that has no immediate bearing on Read. Suffice it to say that Read's book is, therefore, a threefold composition, first an abbreviated edition of Banister's Breviary; secondly a practically complete reprint (for the third time) of J. Guillemeau's book in English, and thirdlyand very much lastly-Read's own effort.

So does Read's 204-page ophthalmic treatise, with its confusing titles and editions, shrink to the small measure of 40 pages vainglorious advertisement of his manual dexterity and his styptic water 
for the cure of blindness and cancer. A sad end for one who, though a quack and mountebank, has been ranked by historians in the illustrious company of pioneer British Ophthalmographers. There is no cause to regret the scarcity of his book. It is best buried under the dust of libraries. In the concluding word he took over from Guillemeau's book: Farewel!

\title{
REFERENCES
}

Hirschberg, J.-In Graefe-Saemisch, 2te. Aufl., Bd. 14, Abth. 1, S. 122, Leipzig, 1911.

Shastid, I. H.-Amer. Encyclop. Ophthal., Vol. IX, p. 8,782, Cleveland, 1917.

James, R. R.-Trans. Ophthal. Soc. U.K., Vol XLI, p. 342, 1921.

\section{A LATE SIXTEENTH CENTURY OPHTHALMIC BOOK IN ENGLISH}

\author{
BY \\ ARNOLD SORSBY
}

LONDON

"A treatise of one hundred and thirteene diseases of the Eyes and. Eye-Liddes," London, 1622, (Fig. 1) is generally regarded as the earliest separate and complete work on eye diseases in English, a view thus expressed by Casey $\mathrm{A}$. Wood ${ }^{1}$ in 1902 , and repeated by him in a qualified form in the American Encyclopedia of Ophthalmology. Even Hirschberg ${ }^{2}$ mistakenly assumes that the first English book on Ophthalmology was Banister's, a view expressed in the first volume of his Geschichte but retracted in the second, where he points out that Banister's book consists largely of an unacknowledged translation from Jacques Guillemeau's Des Maladies de l'Oeil qui sont en Nombre de Cent Treize aux quelles il est Subject" (Paris, 1585). Actually the book passing under Banister's name is a collection of five separate treatises, running to 478 unnumbered pages, of which the first part only, named "Banister's Breviary of the Eyes," running to 112 pages, is his. The bulk of the volume, from p. 113 to p. 367, is taken up by the unacknowledged translation of Guillemeau's book, introduced by a separate title page (Fig. 2). The third section, running to 30 pages, is an unacknowledged reprint of Walter Bailey's " $A$ briefe Treatise concerning the preseruation of the Eye-sight." Рp. 399477 are taken up by an introduction of two pages and by a 41-page "Discourse of the Scorby" and a 34-page essay on "The nature and divers kinds of Cancers or Cankers," the first essay being 